\title{
Investigating the Experience of Boredom During Reading Sessions in the Foreign Language Classroom
}

\author{
Mariusz Kruk \\ University of Zielona Góra \\ Correspondence concerning this article should be addressed to Mariusz Kruk, Wydział Humanistyczny, \\ University of Zielona Góra, al. Wojska Polskiego 71a, 65-762 Zielona Góra, Poland. \\ E-mail: mkanglik@gmail.com
}

\begin{abstract}
Despite the fact that boredom appears to be one of the most commonly experienced emotions in school settings, this negative emotion remains vastly underappreciated in the field of SLA. This is the gap this article seeks to rectify by reporting the findings of a classroom-based study whose purpose was to investigate changes in the experience of boredom in the English language classroom during reading sessions. The sample consisted of 18 second-year students studying English at a Polish high school. The data were collected by means of session logs, observations and reading session plans. The gathered data were analysed quantitatively and qualitatively. The findings showed that the participants reported different levels of boredom over the course of single reading sessions and from one session to the next. Factors responsible for the detected variation in the levels of boredom were related, among other things, to inactivity, performance of too easy/difficult tasks, teacher's decisions regarding choice and use of language materials, the design of the reading sessions or individual characteristics of the learner.
\end{abstract}

Keywords: boredom, changes in the levels of boredom, reading, the English language classroom, learning a foreign language

\section{Introduction}

As indicated by Chapman (2013, p. 1), "boredom in the foreign language classroom is a topic about which much is assumed but little is known." Chapman claims that teachers of foreign languages frequently evade activities that might be perceived by their students as boring, despite the fact that they may have never tried to evaluate their students' views on this problem. For Chapman, the divisions that language teachers make between language exercises that are not boring and those that are, are mostly formed on teachers' own beliefs about what establishes 'good teaching' than on the opinions of real language learners.

Although boredom seems to be part and parcel of learning a foreign language in a classroom setting, few research projects have addressed the issue of boredom among adolescent EFL learners and attempted to investigate its nature. Thus, the study reported in the present paper, which is to some extent a follow-up on the research project carried out by Kruk (2016), tries to shed more light on the problem of boredom in the English language classroom and its dynamic character. The said study focused on several entire lessons in which students performed a combination of activities devoted to practicing different language skills. However, in order to better comprehend the construct of boredom and "to probe deeper to see how boredom is affected by different TL skills" (Pawlak, Zawodniak et al., 2020, p. 96), the present study zeroed in on changes in boredom level during practicing a particular language skill, that is, reading and performing follow-up tasks for reading texts. Thus, this research project aimed at investigating the dynamic character of boredom by tracing its fluctuations during a particular reading session and from one reading session to the next as well as uncovering reasons for such changes. 


\section{Literature review}

\section{Boredom: Theoretical and Empirical Issues}

According to Macklem (2015), boredom can be experienced as an absence of activity and as being disconnected from an interesting task. Bored individuals have "difficulty paying attention, difficulty concentrating, and effort is required to maintain focus on (and not become distracted from) what is going on in the environment" (Macklem, 2015, pp. 1-2). In addition, bored individuals experience disappointment, dissatisfaction, annoyance and/or apathy and they can easily be distracted or not motivated to do what they have planned (Danckert \& Allman, 2005; Fisherl, 1993). Boredom negatively influences student motivation, self-regulated learning, the activation of cognitive resources and achievement (Goetz et al., 2006; Pekrun, 2006). It may contribute to truancy (Sommer, 1985) and drop-out rates (Tidwell, 1988). Boredom is frequently referred to as an affective state that can be characterized by unpleasant feelings, low physiological arousal and the absence of stimulation (Mikulas \& Vodanovich, 1993). It is interesting to note that boredom is "one of the most commonly experienced emotions in many settings" (Pekrun et al., 2010, p. 531) including schools (Macklem, 2015). All in all, boredom may severely impede the learning process, including the process of learning a foreign/second language, and, as a result, make it both less efficient and enjoyable.

Vogel-Walcutt et al. (2012) divided the construct of boredom into trait boredom and state boredom. Trait, or boredom proneness, relates to an individual's propensity to experience feelings of boredom irrespective of settings or conditions. Subjects who are boredom prone appear to be less resistant to boredom provoking situations. Regarding state boredom, it "tends to be operationally defined as the subjective perception of negative affect, the objective assessment of low arousal, or a combination of the two" (Vogel-Walcutt et al., 2012, p. 477). As stated by Belton and Priyadharshini (2007), the development of ways that aim at state boredom and try to reduce it can become of significant value to teachers and may ultimately contribute to improved student performance. It has to be noted that a number of situational factors that increase susceptibility to state boredom in educational settings have been recognized. They involve, among other things, the perception of a task as meaningless, involvement in activities that are abstract and repetitive, excitement lacking, a shortage of appropriate resources, being underchallenged or overchallenged, an absence of impetus or flow, limited control over the process of learning and teachers' decisions (Acee et al., 2010; Hill \& Perkins, 1985; Larson \& Richards, 1991; Preckel et al., 2010; Vogel-Walcutt et al., 2012).

The literature identifies five more types of boredom (Goetz et al., 2014). They encompass: (1) indifferent boredom (i.e., students are relaxed, withdrawn, indifferent), (2) calibrating boredom (i.e., learners are uncertain, receptive to change/distraction), (3) searching boredom (i.e., students are restless and characterized by active pursuit of change/distraction), (4) reactant boredom (i.e., it is characteristic of students who are highly reactant, motivated to leave the situation for specific alternatives) and (5) apathetic boredom (i.e., characterized by extremely unpleasant feelings, students are unmotivated). It is interesting to note that reactant boredom is more intricately connected with learning while indifferent boredom is more linked with leisure time.

As this review of literature indicates, boredom is a complex and multifaceted phenomenon. Boredom is frequently portrayed as the feeling of being disengaged from performing an activity or simply as a type of engagement problem (Macklem, 2015). The complexity of boredom is revealed in the Multidimensional State Boredom Scale (Fahlman et al., 2013) in which disengagement is one of the factors intended to measure boredom. According to Pekrun et al. (2010), boredom cannot be understood as a tantamount to lack of interest since lack of interest can contribute to student boredom. Learners' lack of interest does not involve their willingness to participate in activities nor does it terminate incentives to escape them. It is the unpleasant state of boredom that stimulates students to avoid situations which incite it. Pekrun et al. (2010) view the construct in question as both an activating and deactivating emotion. In more specific terms, individuals may start to seek ways to sustain attention and/or cope with accumulated frustration if a boring task lasts longer than expected. Such a situation may lead to the growth in arousal levels. This demonstrates that in some cases boredom can have a motivational rather than discouraging impact on students (Gumora \& Arsenio, 2002; Valiente et al., 2012). 


\section{L2 Research on Boredom}

When it comes to empirical research into boredom in a foreign language classroom setting, only few studies investigated the issue in question. Some of them dealt with boredom indirectly (e.g., Jean \& Simard, 2011; Kormos \& Csizér, 2014; Peacock, 1997), whereas others had a sharper focus on this phenomenon (e.g., Chapman, 2013; Kruk, 2016; Li, 2021; Li et al., 2021; Nakamura et al., 2021). Since the present study examines fluctuations in boredom, the discussion will focus on the research projects which in their entirety explored changes in the experience of this negative emotion. Regarding the study conducted by Chapman (2013), it explored the beliefs about boredom held by 57 second-year learners of German and their three language teachers. The analysis of the data gathered by means of questionnaires and interviews over a four-week period revealed that the students' attitudes toward their teachers were more accurate predictors of boredom than classroom activities or their features. The researcher also examined the learners' bored behaviours and classified them into active and passive. The former included, for example, the revision of upcoming deadlines, and the latter, encompassed, for instance, daydreaming and talking with a peer. It should be noted, however, that the study suffered from some weaknesses. Among other things, they were related to the definition of boredom (i.e., boredom was considered to be analogous to disinterest), the analysis of activities and activity features (i.e., the relationship between experiences of boredom and repetitive as compared to novel activities was disregarded).

Kruk (2016) carried out a study which investigated changes in the levels of boredom experienced by a group of EFL students $(N=32)$. The study was conducted over a period of three weeks and it comprised eight English lessons. The quantitative and qualitative data analyses allowed the researcher to uncover changes in boredom levels. The reasons for these changes were both general (e.g., the participants' proneness to boredom) and situational (e.g., topics, grammar, the nature of language activities). In a following mixed-methods study, Zawodniak and Kruk (2018) focused on examining the reasons for boredom and changes in its intensity between boredom as experienced in learning the L2 (English) and the L3 (German or French) from a retrospective perspective. The analysis of the data gleaned from a questionnaire revealed fluctuations in boredom levels which were influenced by a host of external (e.g., teacher's involvement in lessons, teacher's attitudes towards students) and internal (e.g., students' expectations, students' language competences) factors. Pawlak, Kruk et al. (2020), in turn, investigated the patterns of boredom experienced in a single English class by five highly and six moderately bored students and whether those patterns were reflected in the individual subjects' trajectories of boredom. The study also sought factors impacting those trajectories. The analysis of the data collected by means of a number of research instruments (e.g., the Boredom in Practical English Language Classes Questionnaire, an in-class boredom questionnaire) revealed that the overall proneness to boredom in English classes was linked to the learners' patterns of boredom which displayed fluctuations in both groups. It has to be noted, however, that there were some differences between the two groups of learners, that is, the moderately bored students showed a gradual growth in the experience of boredom and the highly bored learners exhibited a steadily high level of this negative emotion during the class. The study also demonstrated that the individual trajectories in experiencing boredom frequently departed from the overall patterns and they were shaped by unpredictable constellations of individual and contextual factors. In a more recent study, Kruk et al. (2021) explored changes in the levels of boredom reported by a group of English majors $(N=13)$ in four EFL classes as well as factors influencing such changes. The analysis of the data obtained from a background questionnaire, an in-class boredom questionnaire, a semi-structured interview and lesson plans revealed that although this aversive emotion was attributed to diverse constellations of factors, it was largely tracked to repetitiveness, monotony and predictability of what happened throughout a specific class.

To sum up, the studies described above offer evidence for changes in boredom levels and factors influencing them over time and to the best of the present author's knowledge some of them represent the only published studies which aimed to investigate changes in boredom levels. It should be noted, however, that none of them zooms in on a particular language skill (or a subsystem) and thus they run the risk of overlooking fluctuations in the levels of boredom and factors responsible for such changes in such a context. Thus, the present study attempts to fill this gap by examining changes in the levels of boredom and factors responsible for such variations during reading sessions in which the participants read texts and performed text-related activities. 


\section{Methodology}

\section{Background}

The present study sought to identify changes in boredom levels on a minute-by-minute basis and to uncover factors responsible for such fluctuations. The study followed in the footsteps of researchers who tried to investigate the dynamics of motivation, language anxiety or willingness to communicate in naturally occurring classes (e.g., Kruk, 2018; Mystkowska-Wiertelak \& Pawlak, 2017; Pawlak et al., 2014; Waninge et al., 2014). In line with the earlier research projects, the present study was set in a real classroom, aimed at enhancing ecological validity (Peng, 2014) and thus increasing the relevance of the findings to practitioners.

This research project sought to investigate the changing character of boredom by tracking its fluctuations within a particular reading session as well as from one reading session to another. As such, it concentrated mainly on boredom intensity. In addition, the study explored reasons for such variations. For the purposes of this study, boredom was defined in terms of subjective disengagement, disinterest in and lack of enthusiasm for language tasks being performed. Specifically, this study sought to address the following research questions:

1. How do levels of boredom change over the course of a reading session?

2. How do levels of boredom change from one reading session to another?

3. What factors are responsible for changes in boredom intensity?

\section{Participants}

The learners who participated in this study were 18 second-year male students studying English at a Polish high school. More precisely, the subjects attended a vocational secondary school which also made it more popular for males. The analysis of a background questionnaire (for description of the tool see section Data collection instruments) revealed that the students had been learning English for $10.33(S D=2.22)$ years. Their proficiency level ranged from A2 to B1 (according to the Common European Framework of Reference for Languages) but most of them were rather weak in their command of the target language. This is evident in the fact that their average end-of-the-year grade was $2.56(S D=.70)$ on a scale from 1 (fail) to 6 (excellent). In the subjects' own opinion, however, their level of advancement was slightly higher, as indicated by their selfassessment which amounted to $3.19(S D=.73)$ on the same scale. It should also be noted that the learners had two English lessons per week.

\section{Procedure}

The study was carried out over the period of six weeks in the course of six reading sessions (RS) held within regularly scheduled English lessons. The group was taught by the present author who was also the subjects' regular English teacher. Each reading session lasted approximately 25 minutes and the remainder of each lesson (approximately 20 minutes) was devoted to other classroom activities (e.g., checking homework). All texts and activities used in each reading session were typical of materials used in Polish schools to practice reading comprehension and to prepare students for the Matura examination (i.e., a type of high school finals in Poland) in the English subject at the end of high school.

Figure 1 shows the texts and activities in the first three reading sessions. At the beginning of each reading session the teacher explained some words/phrases from the texts and the students wrote them down in their notebooks. Then, the learners were asked to read a text and perform relevant tasks. After that, the tasks were checked by the teacher who nominated several students to read the answers. 


\section{Figure 1}

Texts and activities in reading sessions 1-3

\begin{tabular}{|c|c|c|}
\hline Reading session 1 & Reading session 2 & Reading session 3 \\
\hline $\begin{array}{l}\text { - a text about Robin Hood } \\
\text { - task 1: a true-false exercise } \\
\text { - task 2: determie the tense used in the } \\
\text { selected sentences }\end{array}$ & $\begin{array}{l}\text { - a text about pubs in Great Britain } \\
\text { - task 1: a multiple-choice activity } \\
\text { - task 2: write a short summary of the } \\
\text { text in Polish }\end{array}$ & $\begin{array}{l}\text { - a text about the Amish } \\
\text { - task } 1 \text { : match headings to paragraphs } \\
\text { - task } 2 \text { : determin the correct part of } \\
\text { speech of ten selected words from the } \\
\text { text }\end{array}$ \\
\hline
\end{tabular}

As for the next three reading sessions, each time the learners were requested to select a text and text-related tasks from a pool of language materials. It should be explained at this juncture that it was a common practice in English lessons to give the students who participated in this study sets of materials to choose from and thus the way the reading sessions were conducted was no exception. The materials included seven different texts and a selection of text-related tasks (e.g., true/false, matching headings to paragraphs, multiple-choice, translations of chosen words, phrases and sentences, paraphrasing, provision of synonyms/antonyms for given words, matching sentence endings, sentence completion). At the start of each reading session (i.e., after a selection of a text) each learner was provided with a list of words (and their explanations) from a specific text. Then the students were requested to read a text and do text-related activities of their own choice. The answers were then collected and checked by the teacher.

\section{Data Collection Instruments}

The data were collected by the following research instruments: a session log, observations and reading session plans, which will be described below.

The session log comprised three parts (see Appendix 1). The first part required the students to provide their name and state the date before the start of each reading session. The second part consisted of a boredom grid in which the students were requested to self-rate their level of boredom six times (i.e., every three minutes) on a scale ranging from 1 (minimum) to 7 (maximum) in response to a sound. The learners were requested to complete this part during each reading session. The internal consistency of this instrument was high $(\alpha=.81)$. The last part of the session log asked the participants to briefly comment on each session, evaluate texts and activities as well as to complete an evaluation scale. The aim of the scale was to obtain information related to the evaluation of reading sessions by the students. The instrument included eight pairs of opposing items (e.g., dull-exciting, unsatisfying-satisfying). Each item was scored on a scale of 1 (minimum) to 7 (maximum). The scale was a modified version of the instrument used by Peacock (1997) and Pawlak (2012). The changes included the deletion/addition of some items and their layout. The learners were requested to complete the evaluation scale immediately after each reading session. The internal consistency of the tool was satisfactory $(\alpha=.69)$.

As for the observations, they provided descriptions of the students' behaviours without unduly affecting the events in which the learners were engaged. Their behaviours were noted down by the researcher/teacher in real time. The reading session plans included detailed information related to reading sessions, their parts and tasks performed by the students.

The instruments were piloted with a group of high school students, not among the participants of the study. The modifications included the following: (1) wording the instruments in the participants' mother tongue (i.e., Polish) in order to avoid misunderstandings and misinterpretations and (2) changing the layout of the session log. It should also be noted that the learners gave their consent to take part in the study and they were informed that their participation in it would not affect their grades in any way.

\section{Analysis}

The numerical data were analyzed by descriptive statistics; mean $(M)$ and standard deviation $(S D)$ values were reported. In addition, the levels of statistical significance were established by means of the nonparametric Wilcoxon Signed-Rank Test. This test was chosen due to the fact that some of the data obtained were not normally distributed. The effect size was computed on the basis of Rosenthal's (1994) formula and interpreted 
as proposed by Plonsky and Oswald (2014). As for the qualitative analysis, it encompassed identification of items or themes included in the students' comments related to texts and activities (i.e., the last part of the session log), as well as in the observations. They were read recurrently in order to detect instances related to the experience of boredom. Notes and annotations were used to document observations. Such data were juxtaposed against reading session plans with reference to the texts, activities and phases of the sessions.

\section{Results}

\section{Changes in the Levels of Boredom during Reading Sessions and Their Causes}

The analysis of the data provided in the boredom grid showed that, overall, the students tended to experience less boredom at the beginning of the reading sessions and they demonstrated more boredom at the end of them (see Figure 2 and Appendix 2). A closer look reveals, however, that the experience of boredom during some of reading sessions (e.g., RS1 and RS3) differed from this general increasing trend and was subject to considerable variation. This is also evident in the values of the standard deviation which demonstrate that the participants varied in their assessment of boredom during the course of the study (see Appendix 2).

\section{Figure 2}

Changes in the levels of boredom during the six reading sessions (RS)

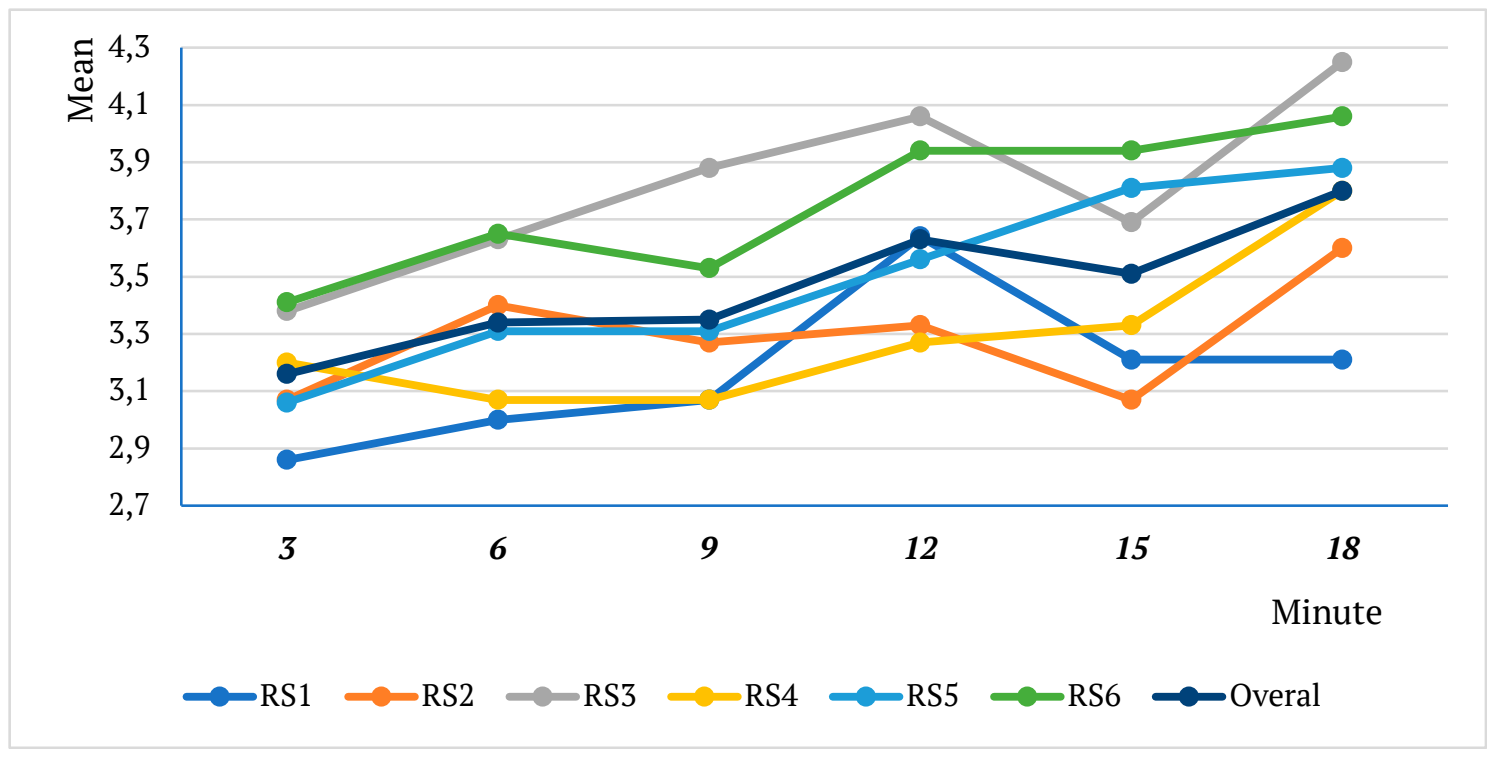

Although a general picture of the changes in boredom levels during the six reading sessions reported by the participants reveals a dynamic character of the construct in question, it fails to provide more detailed information concerning the changes which repeatedly occurred in each session. However, due to space limitations, a detailed description of only three randomly selected reading sessions (i.e., RS1, RS3 and RS5) will be offered here.

As can be seen from Figure 2 and Appendix 2, the students demonstrated relatively low $(M=3.17)$ but fluctuating level of boredom during the course of Reading session 1, since it oscillated between the mean of 2.86 and 3.64 (a difference of .78). The lowest levels of boredom were reported by the participants in the beginning of this session (minutes 3-6), when they started reading the text and in minute 9 (i.e., at the start of the true/false activity). Then a sudden increase in the level of boredom could be observed in minute 12 (i.e., at the end of the true/false activity), followed by a drop of 0.43 from minute 12 to 15 , when the students were asked to determine the tense used in a few selected sentences from the text. The level of boredom remained unchanged till the end of the session (minutes 15 and 18). 
The analysis of the data gleaned from students' comments revealed that most of the subjects perceived the text to be quite interesting; however, a few of them found it quite uninteresting and containing difficult words (e.g., "In my opinion the text was not interesting enough.", "The text was interesting but I didn't understand some words in it." $)$. Most of the students also liked the activities and considered them as interesting and easy to perform; however, few students regarded them as boring and monotonous (e.g., "The text was not bad at all but the exercises were a bit boring.", "The exercises were monotonous and quite boring."). Some learners became bored while waiting for their classmates to finish the activities (e.g., "I experienced boredom only while waiting for others to finish this exercise."). In addition, the analysis of the teacher's notes revealed that those who did the task earlier started to talk to each other or did nothing.

As indicated by the findings in Figure 2 and Appendix 2, there were some changes in the levels of boredom during Reading session 3. More precisely, there was a gradual increase in the level of self-reported boredom from minute 3 to minute 12 (a difference of .68) and a sudden drop in minute 15. This session ended with a sharp increase in the level of boredom (minute 18, $M=4.25$ ). The differences in the levels of boredom between minutes 3-12 and 3-18 turned out to be statistically significant and represented small effect sizes $(Z=2.653, p$ $=.008, r=.47$ and $Z=2.283, p=.022, r=.40$, respectively). When these variations are compared with the session plan, it turns out that the students experienced more boredom at the end of reading the text and at the end of each activity, that is, matching headings to paragraphs and determining the correct part of speech of ten selected words from the text. The analysis of the students' comments revealed that most of them regarded the text and the activities as interesting (e.g., "I liked the text I read today because I learned something new about a different culture and I learned some new, interesting and useful words."); however, for some learners the text and the activities were too easy and thus they considered this session as quite boring (e.g., "The text was interesting but very simple. The first and the second activity were also very simple. I didn't need so much time to do them all and this is why I got bored a bit."). The analysis of the teacher's notes showed that some participants finished reading the text and the follow-up activities earlier. It was observed that those students started to talk to each other, doodled in their notebooks or did nothing.

When it comes to Reading session 5, it involved a text and activities chosen by the subjects from a pool of language materials offered by the teacher. As demonstrated by the findings in Figure 2 and Appendix 2, overall, the learners reported a lower level of boredom throughout this session when compared with Reading session 3 ( $M=3.49$ and $M=3.82$, respectively). It has to be noted, however, that there was a steady growth in the experience of boredom from the start till the end of this session. It is also interesting to observe that the students were less bored in the first half of the session (minutes 3 and 9), which was devoted to reading a selected text, than in its second half (minutes 12 and 18), in which the students continued reading the text and then started solving chosen activities. In addition, the Wilcoxon Signed Rank Test found a statistically significant difference between minutes 3-18 $(Z=2.228, p=.026, r=.39)$. The analysis of the data revealed that most of the students (75\%) chose to read the text about pirates and only few learners (25\%) decided to work with the text about the Bodiam Castle. The students selected these texts either because they were interested in the topic or wanted to read about something new. Additionally, most of the learners (81.25\%) decided to do only one exercise. Relevant excerpts from the students' comments are as follows: "I selected this text because I could learn about something new. Besides, it seemed to be the most interesting.", "The exercise I did was one of the easiest." It was also observed that a few learners occasionally talked to each other throughout the session and a few others recurrently paused for a moment while doing their activities.

\section{Changes in the Levels of Boredom from one Reading Session to Another}

The changes in the experience of boredom from one session to the next were assessed on the basis of the overall mean of boredom grid and the participants' general assessment of sessions (i.e., evaluation scales). As can be seen from Figure 3, the students were the most bored with Reading session 3 and Reading session 6 . However, the experience of boredom during sessions was moderate and oscillated between the values of 3.17 and 3.82 on a seven-point scale. The Wilcoxon Signed Rank Test found some statistically significant differences between different reading sessions: RS1- RS3 ( $Z=2.201, p=.028, r=.64)$, RS1- RS5 $(Z=1.992, p=.046, r=.58)$, RS1- RS6 ( $Z=2.201, p=.028, r=.64)$, RS2- RS3 $(Z=2.201, p=.028, r=.64)$, RS2- RS6 $(Z=2.201, p=.028, r=.64)$, RS3- RS4 ( $Z=2.201, p=.028, r=.64)$, RS3- RS5 $(Z=1.997, p=.046, r=.58)$, RS4- RS6 $(Z=2.201, p=.028, r=.64)$ and RS5- RS6 $(Z=2.201, p=.028, r=.64)$.

These and other excerpts are translations of the students' responses. 


\section{MARIUSZ KRUK}

\section{Figure 3}

Students' evaluations of the reading sessions (based on the evaluation scale)

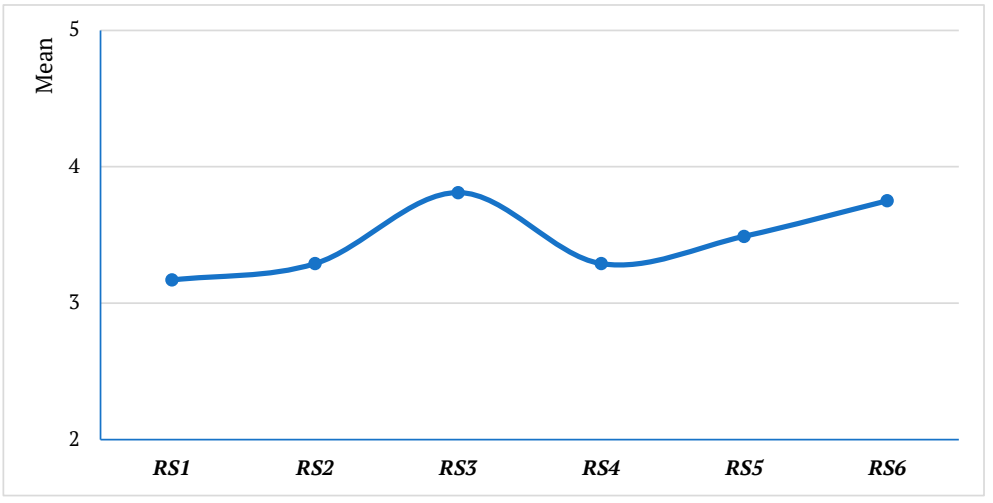

\section{Overall Evaluation of the Reading Sessions}

When it comes to the students' overall evaluation of the reading sessions, it was positive with all the overall mean scores surpassing 4.50 on a 1-7 scale (see Figure 4). In more specific terms, the learners' overall evaluation of the sessions oscillated between the values of 4.56 (RS3) and 5.26 (RS2). The Wilcoxon Signed Rank Test found some statistically significant differences between different reading sessions: RS1- RS2 $(Z=2.103, p=$ $.035, r=.53)$, RS1- RS5 ( $Z=2.521, p=.012, r=.63)$, RS2- RS3 ( $Z=2.380, p=.017, r=.60)$, RS2- RS4 $(Z=2.521, p=$ $.012, r=.63)$, RS2- RS5 ( $Z=2.521, p=.012, r=.63)$, RS2- RS6 ( $Z=2.521, p=.012, r=.63)$, RS4- RS5 $(Z=2.524, p=$ $.012, r=.63)$ and RS5- RS6 $(Z=2.100, p=.036, r=.53)$. In addition, the data show that, overall, the language learners judged the sessions as usual $(M=4.36)$ but mainly meaningful $(M=5.31)$; however, the values of the standard deviation indicate that the group varied in their evaluations of the sessions (for details see Appendix $3)$.

\section{Figure 4}

Students' evaluations of the reading sessions (based on the evaluation scale)

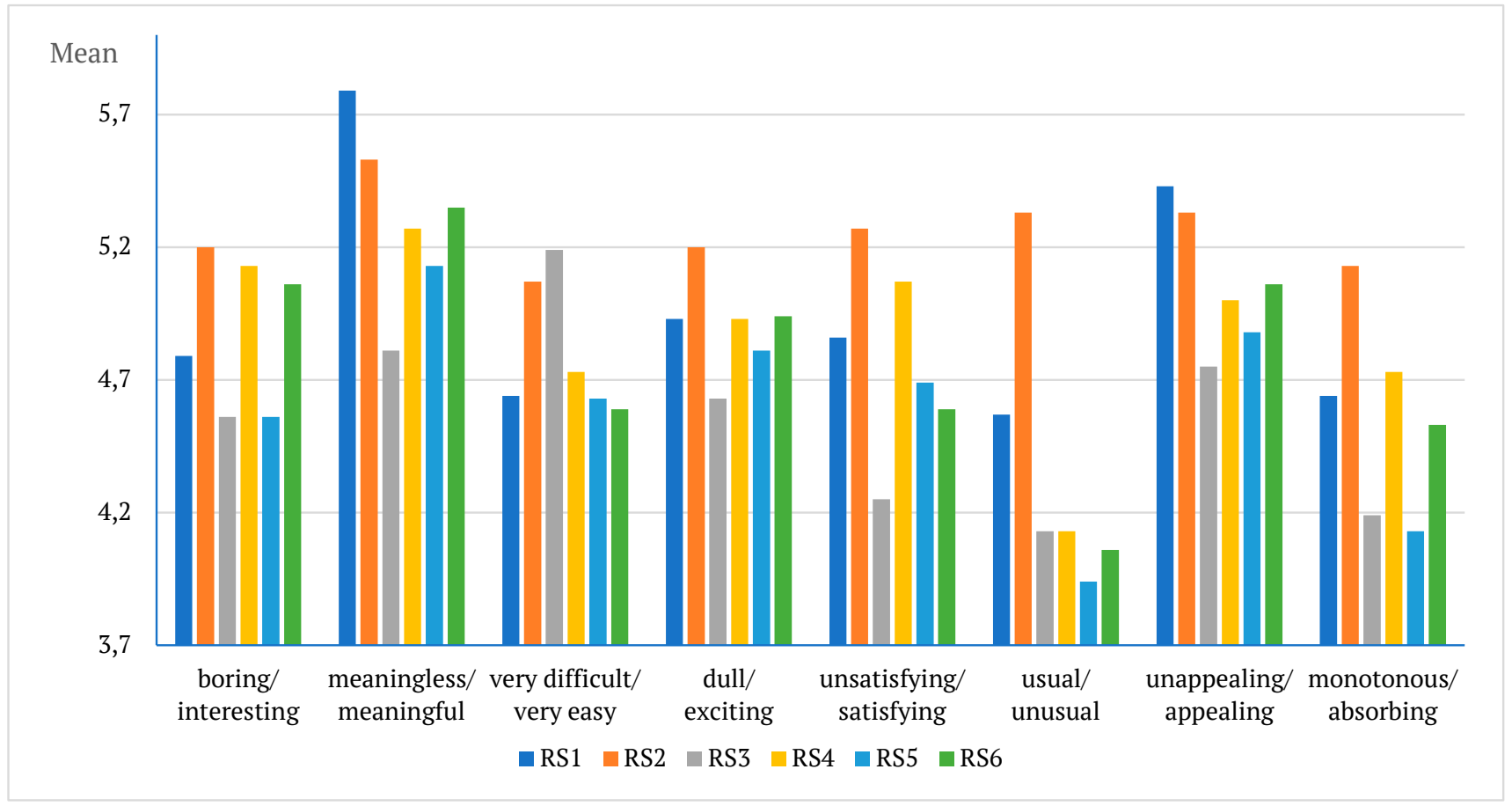




\section{Discussion}

Research questions 1 and 3 aimed to explore changes in the levels of boredom during the six reading sessions and to examine factors responsible for their fluctuations. On the whole, the learners were likely to experience less boredom at the start of the sessions and they tended to exhibit more boredom at the end of them. A closer inspection of the findings revealed, however, that the intensity of boredom throughout some of the sessions differed from this overall increasing pattern and showed that it tended to be less dynamic in the first half of the sessions. Although it could be proposed that the beginning of any new activity is predominantly stimulating for individuals, the analysis of the data demonstrated that the scope and amplitude of the changes could also be ascribed to a variety of factors. They include the attractiveness of texts, the level of difficulty, periods of inactivity and performance of too easy/difficult language activities.

These finding agree with earlier studies that concluded that the level of boredom may be susceptible to being underchallenged or overchallenged (Acee et al., 2010; Larson \& Richards, 1991; Preckel et al., 2010) and prone to the teacher's decisions (Hill \& Perkins, 1985) regarding, for example, the use of language materials in lessons. The findings provide interesting insights which not only confirm the outcomes of previous research projects (e.g., Chapman, 2013; Kruk, 2016), but also can be related to the issues presented in the literature section in this article. This is because the participants may have experienced calibrating and searching boredom (Goetz et al., 2014), particularly in the first three sessions. They may have engaged in off-task thoughts and they may have done more interesting things for them (e.g., talking to a classmate). It is also interesting to observe that the students regarded the selected activities to be very easy during Reading session 5 (also in Reading session 4 and Reading session 6). This finding can be the corollary of the fact that these language learners were allowed to choose texts for themselves from a variety of texts and select additional activities they wanted to perform. However, the steady increase in the levels of boredom in Reading session 5 and higher levels of boredom in the second half of Reading session 4 and Reading session 6 may be the result of time mismanagement and variety lacking. This is because most of the participants devoted too much time to reading and they decided to solve just one task. As a result, the reading part lasted too long and the performance of just one activity may have been perceived by them as monotonous. In addition, and in line with the earlier studies, it could be proposed that the activities the students chose to perform may have been too easy for them and thus they experienced boredom due to being underchallenged (Larson \& Richards, 1991; Preckel et al., 2010; Vogel-Walcutt et al., 2012). It should also be noted that diversity in the values of the standard deviation indicate that the learners varied in their assessment of boredom during the six sessions. As some previous studies indicated, this can be related to individual characteristics of the students, such as individual's propensity to experience boredom (Farmer \& Sundberg, 1986; Pekrun, 2006; Tulis \& Fulmer, 2013; Vogel-Walcutt, et al., 2012) as well as to the fact that the group can be regarded as mixed-proficiency (Pawlak, 2012).

Research questions 2 and 3 focused on the levels of boredom from one session to the next and explored factors responsible for such alterations. Regarding the changes in the experience of boredom, the magnitude of the fluctuations was not very large. Nevertheless, the learners did perceive the sessions differently each time they were asked to evaluate them. For example, it was found that one session in particular was meaningful but dull and the other was usual but easy. Apart from the factors reported above (e.g., being underchallenged or overchallenged, teacher's decisions, time mismanagement), which might also account for the changes in the levels of boredom, these fluctuations may also be related to school subjects scheduled before the English lessons in question or students' weekly workload. In other words, demands of other teachers (e.g., the number of homework assignments, reviewing for tests) might have affected the students' perceptions. The latter factors might cause fatigue among the learners and limit their control over the process of learning, as noted by some researchers (Vogel-Walcutt et al., 2012). This, may ultimately have led to the increased feelings of boredom during some sessions. This explanation should, however, be treated with utmost caution due to the fact that no data on what had happened before or after the lessons were gathered.

All in all, when it comes to the nature of boredom (i.e., its changing character manifested in the fluctuations in the level of boredom observed during the reading sessions and from one session to the next), it makes the phenomenon in question comparable to the nature of motivation, foreign language anxiety and willingness to communicate. This is because the changing character of the latter constructs has been reported in a number of studies (e.g., Kruk, 2018; Mystkowska-Wiertelak \& Pawlak, 2017; Pawlak \& Mystkowska-Wiertelak, 2015; Waninge et al., 2014). 


\section{Conclusion}

Despite the fact that the study offers some useful insights into the nature of boredom in the English language classroom and has ecological validity (cf. Hulstijn, 1997; Lightbown, 2000), it suffers from a number of limitations. They include the small sample size, a limited number of reading sessions, the self-rating procedure, and the fact that data were collected by the participants' regular teacher, which might have prevented them from voicing more critical opinions about the activities they performed. Undoubtedly, the reliability of the present study could have been improved by another pair of observing eyes. It should be noted, however, that similar methodology has been successfully used in other studies (e.g., Pawlak, 2012; Waninge et al., 2014) and it is problematic to find an alternative by means of which requisite real-time data could have been obtained. Future studies should attempt to address these methodological issues. They should include larger samples, a greater number of lessons and refined data collection instruments. Future studies should also involve students of different educational levels and levels of proficiency as well as learners of different foreign/second languages. In addition, future studies might want to investigate the nature of boredom in learning different L2 skills writing and subsystems (e.g., vocabulary, grammar).

Regardless of the limitations of the present study, it has some notable pedagogical implications. One of them relates to the fact that students should be involved in the process of planning parts of a lesson dedicated to reading by, for example, being asked to select reading materials obtained from authentic sources and concerning up-to-date topics. As Belton and Prihadharshini (2007) argue, mitigating boredom in educational settings requires the creation of an environment that promotes learner autonomy, stimulates and motivates students intrinsically. Next, reading texts should vary in style and format in order to avoid monotony and repetitiveness. Reading materials should be adjusted to language learners' proficiency level; however, they should pose a reasonable challenge. Finally, and most importantly perhaps, the teacher's awareness of and desire to combat boredom in the L2 classroom is crucial for creating a genuine and engaging learning environment. Thus, teachers should be aware of the fact that boredom constitutes an inseparable part of foreign/second language classroom environment. Even the most motivated students may suddenly lose their interest in a particular activity if it is too easy/difficult or similar to the one just done, and simply become bored. At the same time boredom is susceptible to change and some suggestions how to alleviate L2 learners' boredom have been given in this article. The implementation of these suggestions may result in language learners' perception of activities as less monotonous, less predictable or dull and may help to reduce the feelings of boredom among learners of foreign/second languages in school settings.

\section{Declaration of Competing Interest}

None declared.

\section{References}

Acee, T. W., Kim, H., Kim, H. J., Kim, J.-I., Chu, H.-N. R., Kim, M., Cho, Y., Wicker, F. W. (2010). Academic boredom in under- and over-challenging situations. Contemporary Educational Psychology, 35(1), 17-27. https://doi. org/10.1016/j.cedpsych.2009.08.002

Belton, T., \& Priyadharshini, E. (2007). Boredom and schooling: A cross-disciplinary exploration. Cambridge Journal of Education, 37(4), 579-595. https://doi.org/10.1080/03057640701706227

Chapman, K. E. (2013). Boredom in the German foreign language classroom [Unpublished doctoral dissertation]. University of Wisconsin-Madison.

Cohen, J. (1988). Statistical power analysis for the behavioral sciences (2nd ed.). Lawrence Earlbaum Associates.

Danckert, J. A., \& Allman, A. A. (2005). Time flies when you're having fun: Temporal estimation and the experience of boredom. Brain and Cognition, 59(3), 236-245. https://doi.org/10.1016/j.bandc.2005.07.002

Fahlman, S. A., Mercer-Lynn, K. B., Flora, D. B., \& Eastwood, J. D. (2013). Development and validation of the Multidimensional State Boredom Scale. Assessment, 20(1), 68-85. https://doi. org/10.1177\%2F1073191111421303

Farmer, R., \& Sundberg, N., D. (1986). Boredom proneness: The development and correlates of a new scale. Journal of Personality Assessment, 50, 4-17. https://doi.org/10.1207/s15327752jpa5001_2 
Fisherl, C. D. (1993). Boredom at work: A neglected concept. Human Relations, 46(3), 395-417. https://doi.org/1 $0.1177 \% 2 F 001872679304600305$

Goetz, T., Pekrun, R., Hall, N. \& Haag, L. (2006). Academic emotions from a social-cognitive perspective: Antecedents and domain specificity of students' affect in the context of Latin instruction. British Journal of Educational Psychology, 76, 289-308. https://doi.org/10.1348/000709905x42860

Goetz, T., Frenzel, A. C., Hall, N. C., Nett, U. E., Pekrun, R. \& Lipnevich, A. A. (2014). Types of boredom: An experience sampling approach. Motivation and Emotion, 38(3), 401-419. https://psycnet.apa.org/doi/10.1007/ s11031-013-9385-y

Gumora, G., \& Arsenio, W.F. (2002). Emotionality, emotion regulation, and school performance in middle school children. Journal of School Psychology, 40, 395-413. https://doi.org/10.1016/S0022-4405(02)00108-5

Hill, A. B., \& Perkins, R. E. (1985). Towards a model of boredom. British Journal of Psychology, 76(2), 235-240. https://doi.org/10.1111/j.2044-8295.1985.tb01947.x

Hulstijn, J. (1997). Second language acquisition research in the laboratory: Possibilities and limitations. Studies in Second Language Acquisition, 19, 131-43. https://doi.org/10.1017/S0272263197002015

Jean, G., \& Simard, D. (2011). Grammar teaching and learning in L2: Necessary, but boring? Foreign Language Annals, 44(3), 467-494. https://doi.org/10.1111/j.1944-9720.2011.01143.x

Kormos, J., \& Csizér, K. (2014). The interaction of motivation, self-regulatory strategies, and autonomous learning bevavior in different learner groups. TESOL Quarterly, 48(2), 275-299. https://doi.org/10.1002/ tesq. 129

Kruk, M. (2016). Investigating the changing nature of boredom in the English language classroom: Results of a study. In A. Dłutek, \& D. Pietrzak (Eds.), Nowy wymiar filologii (pp. 252-263). Wydawnictwo Naukowe Państwowej Wyższej Szkoły Zawodowej w Płocku.

Kruk, M. (2018). Changes in foreign language anxiety: A classroom perspective. International Journal of Applied Linguistics, 28(1), 31-57. https://doi.org/10.1111/ijal.12182

Kruk, M., Pawlak, M., \& Zawodniak, J. (2021). Another look at boredom in language instruction: The role of the predictable and the unexpected. Studies in Second Language Learning and Teaching, 11(1), 15-40. http:// dx.doi.org/10.14746/ssllt.2021.11.1.2

Larson, R. W., \& Richards, M. H. (1991). Boredom in the middle school years: Blaming schools versus blaming students. American Journal of Education, 99(4), 418-433. https://psycnet.apa.org/doi/10.1086/443992

$\mathrm{Li}, \mathrm{C}$. (2021). A control-value theory approach to boredom in English classes among university students in China. Modern Language Journal, 1(105), 317-334. https://doi.org/10.1111/modl.12693

$\mathrm{Li}, \mathrm{C}$., Dewaele, J.-M., \& Hu, Y. (2021). Foreign language learning boredom: Conceptualization and measurement. Applied Linguistics Review, paper 00001015152020012. https://doi.org/10.1515/applirev-2020-0124

Lightbown, P. (2000). Anniversary article: Classroom SLA research and second language teaching. Applied Linguistics, 21, 431-462. https://doi.org/10.1093/applin/21.4.431

Macklem, G. L. (2015). Boredom in the classroom: Addressing student motivation, self-regulation, and engagement in learning. Springer International Publishing.

Mikulas, W. L., \& Vodanovich, S. J. (1993). The essence of boredom. Psychological Record, 43, 3-12.

Mystkowska-Wiertelak, A., \& Pawlak, M. (2017). Willingness to communicate in instructed second language acquisition: Combining a macro- and micro-perspective. Multilingual Matters

Nakamura, S., Darasawang, P., \& Reinders, H. (2021). The antecedents of boredom in L2 classroom learning. System, 98, paper 102469. https://doi.org/10.1016/j.system.2021.102469

Pawlak, M. (2012). The dynamic nature of motivation in language learning. Studies in Second Language Learning and Teaching, 2(2), 249-278. https://doi.org/10.14746/ssllt.2012.2.2.7

Pawlak, M., Kruk, M., \& Zawodniak, J. (2020). Investigating individual trajectories in experiencing boredom in the language classroom: The case of 11 Polish students of English. Language Teaching Research. https://doi. org/10.1177\%2F1362168820914004

Pawlak, M., \& Mystkowska-Wiertelak, A. (2015). Investigating the dynamic nature of L2 learners' willingness to communicate. System, 50, 1-9. http://dx.doi.org/10.1016\%2Fj.system.2015.02.001

Pawlak, M., Mystkowska-Wiertelak, A., \& Bielak, J. (2014). Another look at temporal variation in language learning motivation: Results of a study. In M. Pawlak, \& L. Aronin (Eds.), Essential topics in applied linguistics and bilingualism: Studies in honor of David Singleton (pp. 89-109). Springer.

Pawlak, M., Zawodniak, J., \& Kruk., M. (2020). Boredom in the foreign language classroom: A micro-perspective. Springer.

Peacock, M. (1997). The effect of authentic materials on the motivation of EFL learners. ELT Journal, 51, 144-156. https://doi.org/10.1093/elt/51.2.144 


\section{MARIUSZ KRUK}

Pekrun, R. (2006). The control-value theory of achievement emotions: Assumptions, corollaries, and implications for educational research and practice. Educational Psychology Review, 18(4), 315-341. https://doi.org/10.1007/ s10648-006-9029-9

Pekrun, R., Goetz, T., Daniels, L. M., Stupnisky, R. H., \& Perry, R. (2010). Boredom in achievement settings: Exploring control-value antecedents and performance outcomes of a neglected emotion. Journal of Educational Psychology, 102(3), 531-549. https://psycnet.apa.org/doi/10.1037/a0019243

Peng, J. E. (2014). Willingness to communicate inside the EFL classroom: An ecologica perspective. Multilingual Matters.

Plonsky, L., \& Oswald, F. L. (2014). How big is "big”? Interpreting effect sizes in L2 research. Language Learning, 64, 878-912. https://doi.org/10.1111/lang.12079

Preckel,F., Götz, T., \& Frenzel,A. (2010). Ability grouping of gifted students: Effects on academic self-concept and boredom. British Journal of Educational Psychology,80(3), 451-472.https://doi.org/10.1348/000709909x480716

Rosenthal, R. (1994). Parametric measures of effect size. In H. Cooper, \& L. V. Hedges (Eds.), The handbook of research synthesis (pp. 231-244). Russell Sage Foundation.

Sommer, B. (1985). What's different about truants? A comparison study of eighth-graders. Journal of Youth and Adolescence, 14(5), 411-422. https://doi.org/10.1007/bf02138836

Tidwell, R. (1988). Dropouts speak out: Qualitative data on early school departures. Adolescence, 23(92), 939-954.

Tulis, M., \& Fulmer, S. M. (2013). Students' motivational and emotional experiences and their relationship to persistence during academic challenge in mathematics and reading. Learning and Individual Differences, 27, 35-46. https://doi.org/10.1016/j.lindif.2013.06.003

Valiente, C., Swanson, J., \& Eisenberg, J. (2012). Linking students' emotions and academic achievement: When and why emotions matter. Child Development Perspectives, 6(2), 129-135. https://dx.doi.org/10.1111\%2Fj.17508606.2011.00192.x

Vogel-Walcutt, J. J., Abich, J., \& Schatz, S. (2012). Boredom in learning. In N. Seel, \& M. Norbert (Ed.), Encyclopedia of the sciences of learning (pp. 477-479). Springer.

Vogel-Walcutt, J. J., Logan, F., Carper, T., \& Schatz, S. (2012). The definition, assessment, and mitigation of state boredom within educational settings: A comprehensive review. Educational Psychology Review, 24(1), 89-111. https://doi.org/10.1007/s10648-011-9182-7

Waninge, F., Z. Dörnyei, \& de Bot, K. (2014). Motivational dynamics in language learning: Change, stability, and context. Modern Language Journal, 98(3), 704-723. https://doi.org/10.1111/modl.12118

Zawodniak, J. \& Kruk, M. (2018). Porównawcze studium doświadczania nudy w nauce języków drugiego i trzeciego [A comparative study of the experience of boredom in L2 and L3 acquisition]. Applied Linguistics Papers, 25(3), 149-163. https://doi.org/10.32612/uw.25449354.2018.3.pp.149-163 


\section{INVESTIGATING THE EXPERIENCE OF BOREDOM DURING READING SESSIONS}

\section{Appendix 1}

\section{Session log.}

Part I: Before the reading session

Please state your name Date .

Part II: During the reading session

Please indicate your level of boredom every time you will hear a sound. Use a scale of 1 - 7. If you are very bored write 7 and if are not bored at all write 1.

\begin{tabular}{lcccccc}
\hline & Minute 3 & Minute 6 & Minute 9 & Minute 12 & Minute 15 & Minute 18 \\
\hline Level of boredom & & & & & &
\end{tabular}

Part III: After the reading session

Now briefly comment on the text and activities:

Please mark your responses with an (x) in between one of the seven spaces which best represents your feelings of the text and activities.

\begin{tabular}{|l|l|l|l|l|l|l|r|}
\hline boring & & & & & & & interesting \\
\hline meaningless & & & & & & & meaningful \\
\hline very difficult & & & & & & & very easy \\
\hline dull & & & & & & & exciting \\
\hline unsatisfying & & & & & & & satisfying \\
\hline usual & & & & & & & unusual \\
\hline unappealing & & & & & & & appealing \\
\hline monotonous & & & & & & & absorbing \\
\hline
\end{tabular}




\section{MARIUSZ KRUK}

\section{Appendix 2}

The mean and standard deviation values during all reading sessions (RS)

\begin{tabular}{cccccccc}
\hline \multirow{2}{*}{$\boldsymbol{R} \boldsymbol{S}$} & $\boldsymbol{m} \boldsymbol{m}$. 3 & min. 6 & min. 9 & min. 12 & min. 15 & min. 18 & Overall \\
\cline { 2 - 7 } & Mean (SD) & & & & & & \\
\hline 1 & $2.86(0.86)$ & $3.00(1.18)$ & $3.07(1.27)$ & $3.64(1.55)$ & $3.21(1.42)$ & $3.21(1.42)$ & $3.17(0.27)$ \\
2 & $3.07(1.28)$ & $3.40(1.12)$ & $3.27(1.16)$ & $3.33(1.40)$ & $3.07(1.28)$ & $3.60(1.35)$ & $3.29(0.20)$ \\
3 & $3.38(1.15)$ & $3.63(1.26)$ & $3.88(1.36)$ & $4.06(1.00)$ & $3.69(1.20)$ & $4.25(1.57)$ & $3.82(0.31)$ \\
4 & $3.20(1.47)$ & $3.07(1.22)$ & $3.07(1.16)$ & $3.27(1.03)$ & $3.33(1.59)$ & $3.80(1.93)$ & $3.29(0.27)$ \\
5 & $3.06(1.44)$ & $3.31(1.45)$ & $3.31(1.30)$ & $3.56(1.41)$ & $3.81(1.42)$ & $3.88(1.50)$ & $3.49(0.32)$ \\
6 & $3.41(1.77)$ & $3.65(1.54)$ & $3.53(1.50)$ & $3.94(1.56)$ & $3.94(1.43)$ & $4.06(1.75)$ & $3.76(0.26)$ \\
Overall & $3.16(0.21)$ & $3.34(0.27)$ & $3.35(0.31)$ & $3.63(0.32)$ & $3.51(0.35)$ & $3.80(0.36)$ & \\
\hline
\end{tabular}

Note: "min" refers to "minute" 
INVESTIGATING THE EXPERIENCE OF BOREDOM DURING READING SESSIONS

\section{Appendix 3}

The mean and standard deviation values for the students' evaluation of the reading sessions (RS)

\begin{tabular}{|c|c|c|c|c|c|c|c|c|c|}
\hline$R S$ & $\begin{array}{c}\text { boring } \\
\text { interesting }\end{array}$ & $\begin{array}{c}\text { meaningless } \\
\text { meaningful }\end{array}$ & $\begin{array}{c}\text { very } \\
\text { difficult } \\
\text { very easy }\end{array}$ & $\begin{array}{c}\text { dull } \\
\text { exciting }\end{array}$ & $\begin{array}{c}\text { unsatisfying } \\
\text { satisfying }\end{array}$ & $\begin{array}{c}\text { usual } \\
\text { unusual }\end{array}$ & $\begin{array}{c}\text { unappealing } \\
\text { appealing }\end{array}$ & $\begin{array}{c}\text { monotonous } \\
\text { absorbing }\end{array}$ & Overall \\
\hline & \multicolumn{9}{|l|}{ Mean (SD) } \\
\hline \multirow[t]{2}{*}{1} & 4.79 & 5.79 & 4.64 & 4.93 & 4.86 & 4.57 & 5.43 & 4.64 & 4.96 \\
\hline & (1.58) & $(1.25)$ & (1.34) & $(1.00)$ & (1.17) & $(1.40)$ & (1.16) & $(1.50)$ & $(0.43)$ \\
\hline \multirow[t]{2}{*}{2} & 5.20 & 5.53 & 5.07 & 5.20 & 5.27 & 5.33 & 5.33 & 5.13 & 5.26 \\
\hline & (1.74) & (1.13) & (1.16) & (1.26) & (1.44) & $(1.50)$ & $(1.45)$ & $(1.41)$ & $(0.14)$ \\
\hline \multirow[t]{2}{*}{3} & 4.56 & 4.81 & 5.19 & 4.63 & 4.25 & 4.13 & 4.75 & 4.19 & 4.56 \\
\hline & (1.21) & $(0.91)$ & $(1.22)$ & $(0.89)$ & (1.29) & $(1.41)$ & $(1.24)$ & $(1.22)$ & $(0.36)$ \\
\hline \multirow[t]{2}{*}{4} & 5.13 & 5.27 & 4.73 & 4.93 & 5.07 & 4.13 & 5.00 & 4.73 & 4.87 \\
\hline & (1.06) & (1.28) & (1.03) & $(0.80)$ & (1.16) & $(1.92)$ & (1.13) & $(0.88)$ & $(0.35)$ \\
\hline \multirow[t]{2}{*}{5} & 4.56 & 5.13 & 4.63 & 4.81 & 4.69 & 3.94 & 4.88 & 4.13 & 4.60 \\
\hline & (1.31) & $(1.20)$ & (1.63) & $(0.98)$ & $(1.20)$ & $(2.05)$ & (1.09) & (1.26) & (0.39) \\
\hline \multirow[t]{2}{*}{6} & 5.06 & 5.35 & 4.59 & 4.94 & 4.59 & 4.06 & 5.06 & 4.53 & 4.77 \\
\hline & $(1.60)$ & $(1.17)$ & $(1.00)$ & $(1.34)$ & $(1.28)$ & $(1.39)$ & $(1.25)$ & $(1.59)$ & $(0.41)$ \\
\hline \multirow{2}{*}{ Total } & 4.88 & 5.31 & 4.81 & 4.91 & 4.79 & 4.36 & 5.08 & 4.56 & \\
\hline & (0.29) & $(0.34)$ & $(0.26)$ & (0.19) & $(0.36)$ & $(0.52)$ & $(0.26)$ & (0.37) & \\
\hline
\end{tabular}

